\title{
miR-181 and Metabolic Regulation in the Immune System
}

\author{
Adam Williams, ${ }^{1,4}$ Jorge Henao-Mejia, ${ }^{1,4}$ Christian C. D. Harman, ${ }^{2}$ \\ AND Richard A. Flavell ${ }^{1,3,5}$ \\ ${ }^{1}$ Department of Immunobiology, Yale University School of Medicine, New Haven, Connecticut 06520 \\ ${ }^{2}$ Department of Genetics, Yale University School of Medicine, New Haven, Connecticut 06520 \\ ${ }^{3}$ Howard Hughes Medical Institute, Chevy Chase, Maryland 20815-6789 \\ ${ }^{5}$ Correspondence: richard.flavell@yale.edu
}

\begin{abstract}
Regulation of metabolism is emerging as a central mechanism to control cellular identity and function. Extensive research in the last few years has revealed that the PI3K pathway is at the forefront of establishing metabolic changes required for immune cell growth, proliferation, migration, and differentiation. However, we currently have a limited understanding of how signaling through the PI3K pathway is tightly regulated during immune responses and immune cell development. Although a growing number of miRNAs have been shown to target important metabolic pathways, including the PI3K pathway itself, almost nothing is known regarding metabolic regulation by miRNAs in the context of the immune system. Recently, we revealed that the miR-181 family is a metabolic rheostat in vivo through the nonredundant regulation of PTEN. Over the next few years, additional miRNAs with the capacity to regulate various aspects of metabolism in immune cells are likely to be identified. We propose that these miRNAs will form a network to finely tune cellular metabolic status and that miR-181 will function as the primary metabolic rheostat of this network.
\end{abstract}

Glucose, the main nutrient for mammalian cells, is used to obtain energy to sustain cellular processes through two integrated pathways: glycolysis and tricarboxylic acid (TCA) cycle. During glycolysis, glucose is converted to pyruvate through a series of enzymatic reactions in which phosphates are transferred from glycolytic intermediaries to generate ATP. Glycolysis and the TCA cycle are interconnected when pyruvate is converted into acetyl-CoA, which enters the TCA cycle in the mitochondria. In this second pathway, reducing equivalents (nicotinamide adenine dinucleotide [NADH] and flavin adenine dinucleotide $[\mathrm{FADH}]$ ) are generated to serve as electron donors for the electron transport chain to fuel oxidative phosphorylation (OXPHOS). Glycolysis generates two ATPs per molecule of glucose, whereas OXPHOS generates up to 36 ATPs per glucose molecule. Under particular physiological conditions, cells also have the capability to metabolize other substrates (i.e., glutamine or fatty acids) to replenish the TCA cycle and promote OXPHOS. As multiple metabolic pathways intersect with each other at many levels in different cell types and conditions, eukaryotic cells face choices as to how to attain their metabolic goals (Pearce and Pearce 2013).

Until recently cellular metabolism was considered a "housekeeping" utility that merely supported cellular processes essential for survival through the production of ATP. However, it is now clear that the regulation of metabolic pathways provides a mechanism to actively control cellular growth and proliferation. The diametrically opposite cellular metabolic processes that are performed in quiescent and proliferating cells clearly exemplify this paradigm. Quiescent cells mainly rely on mitochondrial OXPHOS to generate energy, whereas proliferating cells metabolize nutrients primarily through aerobic glycolysis as a means to divert glycolytic intermediaries into biomass required to sustain proliferation (Vander Heiden et al. 2009). Recent work focused on immune cells has further expanded our understanding of how metabolism impacts physiology; indeed, it is now evident that metabolic choices can also dictate cellular function and fate.

\section{CELLULAR METABOLISM IN THE ADAPTIVE IMMUNE SYSTEM}

Development of the immune system requires a series of proliferation events that are coupled to differentiation programs; thus, developing immune cells must adapt their cellular metabolism to provide the building blocks required for high rates of proliferation and to maintain the quiescent state of specialized cellular populations. At the functional level, immune responses are a process of clonal expansion that requires rapid bursts of proliferation; moreover, it involves the differentiation of distinct functional cell subsets that depend on unique cellular metabolic processes (Pearce and Pearce 2013). Thus, lymphopoiesis, myelopoiesis, and immune responses represent the best example in mammalian organisms in which coordinated changes in cellular metabolism are essential to accomplish key physiological goals (Pearce and Pearce 2013).

In the context of the immune system, changes in cellular metabolism are primarily imposed by growth factors, cytokines, and receptors present in myeloid and lymphoid cell subsets (i.e., Toll-like receptors, costimulatory receptors). Therefore, evolutionarily conserved

\footnotetext{
${ }^{4}$ A.W. and J.H.-M. contributed equally.

Copyright (C) 2013 Cold Spring Harbor Laboratory Press; all rights reserved; doi: 10.1101/sqb.2013.78.020024

Cold Spring Harbor Symposia on Quantitative Biology, Volume LXXVIII
} 
signaling pathways activated by extracellular cues have the instructive role of reprogramming cellular metabolism in response to changes in the extracellular environment. In recent years, the phosphatidylinositol 3-kinase (PI3K) pathway has emerged as a central regulator of both growth control and glucose metabolism (Fox et al. 2005). Activation of PI3K results in the conversion of phosphatidylinositol-4,5-bisphosphate $\left(\mathrm{PIP}_{2}\right)$ to phosphatidylinositol-3,4,5-triphosphate $\left(\mathrm{PIP}_{3}\right)$. Accumulation of $\mathrm{PIP}_{3}$ recruits the serine/threonine-specific protein kinase AKT to the plasma membrane where it is activated by PDK1 and mTORC2 (Song et al. 2012). Active AKT serves as a regulatory hub of cell cycle progression and anabolic metabolism through factors such as GSK $3 \beta$, mTORC1, and FOXO proteins. In particular, activation of AKT leads to the up-regulation of glucose transporter expression, enhances glucose capture by hexokinase, and stimulates the activity of downstream glycolytic enzymes, which renders proliferating immune cells highly dependent on elevated levels of glucose flux. Thus, signaling through the PI3K pathway is now considered essential for the proper metabolic performance of the immune system.

In naïve and effector T cells, ligation of the costimulatory molecule CD28 activates the PI3K pathway and a metabolic switch (Parry et al. 1997; Summers et al. 1999; Frauwirth and Thompson 2002). It enhances glucose uptake and its utilization through increasing the expression of the glucose transporter Glut1 and by promoting glycolysis reactions by elevating hexokinase activity and phosphorylating PFK-2, which leads to increased fructose-2,6-bisphospate levels and increased glycolysis (Ueki et al. 1998; Barthel et al. 1999; Gottlob et al. 2001; Frauwirth and Thompson 2002; Jacobs et al. 2008). In concordance, activation of the inhibitory CD28 family member CTLA-4 blocks PI3K signaling and T-cell proliferation (Frauwirth and Thompson 2002). Downstream from AKT, the mTOR pathway induces cell growth during T-cell activation through well-defined mechanisms that include up-regulation of aminoacid transporters, activation of glycolytic pathways, and promotion of initiation of cap-dependent translation (Cobbold et al. 2010; Chi 2012). The essential role of mTOR as a regulator of the metabolism of activated $\mathrm{T}$ cells and their differentiation is highlighted by the potent immunosuppressive activity of the mTOR inhibitor rapamycin, which induces cell cycle arrest of activated T cells (Lopez-Rios et al. 2007). Furthermore, rapamycin treatment increases the number of memory CD8 T-cell precursors and accelerates the memory T-cell differentiation program enhancing not only the quantity but also the quality of memory CD8 T cells during viral infection (Araki et al. 2009). In addition, mTOR activity is absolutely required for the differentiation of effector T cells. Specifically, mTORC1 promotes Th1 and Th17 differentiation, whereas mTORC2 regulates the generation of Th2 cells (Chi 2012). In conclusion, metabolic changes induced by the PI3K pathway are not only essential for the rapid clonal expansion and growth of $\mathrm{T}$ cells but also for their differentiation into distinct subsets.
Migration of lymphocytes from mucosal surfaces to secondary lymphoid organs is an energy-demanding process. As such, recent evidence also indicates that the PI3K-AKT-mTOR "metabolic" axis also influences this sequence of events during immune responses. PI3K signaling results in the down-regulation of CD62L, CCR7, and S1P1, which are important for homing to and retention in secondary lymphoid organs. In concordance, induction of PI3K-mTOR activation leads to the up-regulation of surface molecules required for homing to peripheral organs such as VLA4, CXCR3, CCR5, and $\mathrm{P}$ and E-selectin ligands. Furthermore, rapamycin treatment causes the re-expression of CD62L and CCR7, inducing the retention of effector $\mathrm{T}$ cells in secondary lymph organs (Sinclair et al. 2008).

Extensive research in the last lustrum has led to important advances in our understanding of the basic concepts of cellular metabolism in the immune system; moreover, these studies have centered the PI3K pathway at the forefront of metabolic changes required for cell growth, proliferation, migration, and differentiation. However, we have extremely limited knowledge of how signaling through the PI3K pathway is tightly regulated during immune responses and development. As deviations from the strict limits of immune cell metabolism might result in lymphproliferation, lymphopenia, autoimmunity, immunodeficiency, or cancer, it is essential that we understand how cellular metabolism is regulated. With respect to this point, it is worth noting that the role of noncoding RNAs in the regulation of immune cell metabolism remain largely unexplored.

\section{PTEN: AN OPTIMAL TARGET FOR miRNA-MEDIATED REGULATION OF CELLULAR METABOLISM}

The principle negative regulator of the PI3K pathway is the $3^{\prime}$-phosphate lipid phosphatase PTEN (phosphatase and tensin homolog), which dephosphorylates $\mathrm{PIP}_{3}$ to $\mathrm{PIP}_{2}$ thereby preventing its accumulation (Myers et al. 1998). PTEN is one of the most commonly mutated tumor-suppressor genes in human cancer; reduced expression or function of PTEN results in elevated PI3K signaling leading to unrestrained proliferation, growth, and metabolic changes associated with tumor progression (Song et al. 2012). Interestingly, cells are exquisitely sensitive to levels of PTEN and even modest changes in PTEN can have dramatic effects on cellular physiology, especially in cellular metabolic functions (Alimonti et al. 2010; Garcia-Cao et al. 2012; Ortega-Molina et al. 2012). Thus, robust mechanisms must therefore exist to precisely control PTEN expression, and regulation by miRNAs provides one exciting possibility (Xiao et al. 2008; Alimonti et al. 2010; Lee et al. 2010; Poliseno et al. 2010; Zhang et al. 2010; Jiang et al. 2011; Karreth et al. 2011). MicroRNAs (miRNA) are $~ 20-24$-nucleotide-long endogenous RNAs, which are now considered fundamental components of the regulatory system of eukaryotic gene expression (Ebert et al. 2009). miRNAs repress gene 
expression through direct binding to the $3^{\prime}$ untranslated region (UTR) of target messenger RNA (mRNA) (Ebert et al. 2009). Typically, miRNA-target interactions produce only subtle $(<2$ fold) reductions in protein levels, leading to the suggestion that miRNAs may function as "fine tuners" to stabilize transcriptional networks and confer system robustness to complex developmental pathways (Ebert et al. 2009).

Although miRNAs have been shown to target PTEN in vitro, the physiological relevance of these interactions remains to be established, especially when considering the general lack of gross phenotypes in miRNA knockout mice. Furthermore, although direct regulation of PTEN by miRNAs during cancer progression has been reported, targeted deletion of these miRNAs does not cause overt developmental or growth phenotypes that are normally associated with metabolic deficits associated with aberrant PI3K signaling, suggesting that they have a negligible role in regulating metabolic homeostasis in vivo (Ventura et al. 2008; Olive et al. 2009; Patrick et al. 2010; Ma et al. 2011). In contrast, we recently identified the miR-181 microRNA family as a bona fide in vivo metabolic regulator. Unlike most miRNAs knockouts, miR-181-deficient mice displayed robust phenotypes associated with impaired metabolic fitness (Fig. 1) (HenaoMejia et al. 2013).

\section{miR-181 IS A NONREDUNDANT METABOLIC RHEOSTAT}

Using an in silico approach to search for miRNAs with the capacity to regulate PI3K pathway, we discovered four predicted (Dianalab algorithm) miR-181 sites in the $3^{\prime}$ UTR of Pten. The miR-181 family is composed of six mature miRNAs: miR-181a-1, miR-181a-2, miR181b-1, miR-181b-2, miR-181c, and miR-181d, which are encoded in three independent paralog precursor transcripts on three separate chromosomes (Ji et al. 2009). In terms of sequence homology, the mature forms of miR181a-1 and miR-181a-2, as well as miR-181b-1 and miR$181 \mathrm{~b}-2$, are identical. Furthermore, all family members contain the same 5 " seed" sequence suggesting a significant degree of functional redundancy (Ji et al. 2009). The miR-181 family is one of the most highly expressed miRNA families in many tissues, including the immune system. Furthermore, miR-181a1/b1 is preferentially and highly expressed in the thymus, which is a highly proliferative tissue with large metabolic requirements. Thus, the miR-181 family represents an ideal candidate for a global and tissue-specific metabolic regulator (Kuchen et al. 2010). To test the ability of the miR-181 family to regulate PTEN in vivo, we generated mice deficient in each of the three mir-181 gene clusters. As hypothesized, thymocytes from miR-181a1/b1-deficient mice displayed elevated PTEN levels and a concomitant reduction in PI3K signaling. Strikingly this led to the dysregulation of thousands of genes; such large changes in gene expression are unusual in miRNA knockout animals reflecting the nonredundant role of the miR-181 family.

Activation of the PI3K pathway provides a potent stimulus for proliferation and growth during $\mathrm{T}$-cell and NKT-cell development in the thymus. To produce two daughter cells at mitosis, a proliferating cell must replicate all of its cellular components. This imposes a large
WT

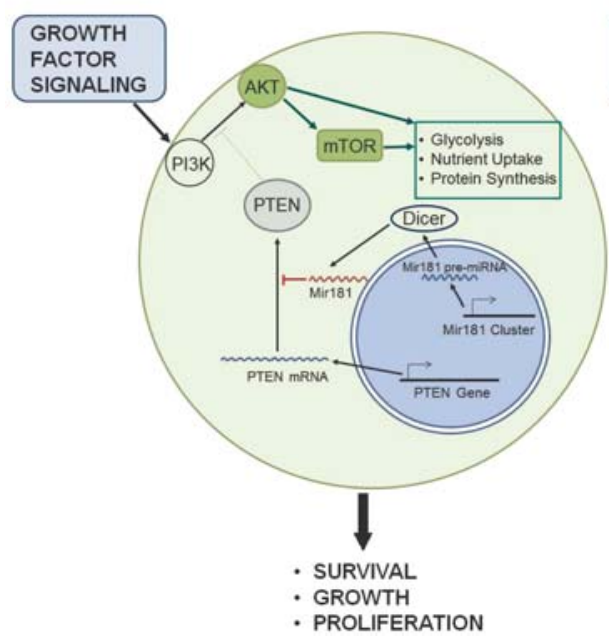

Ko

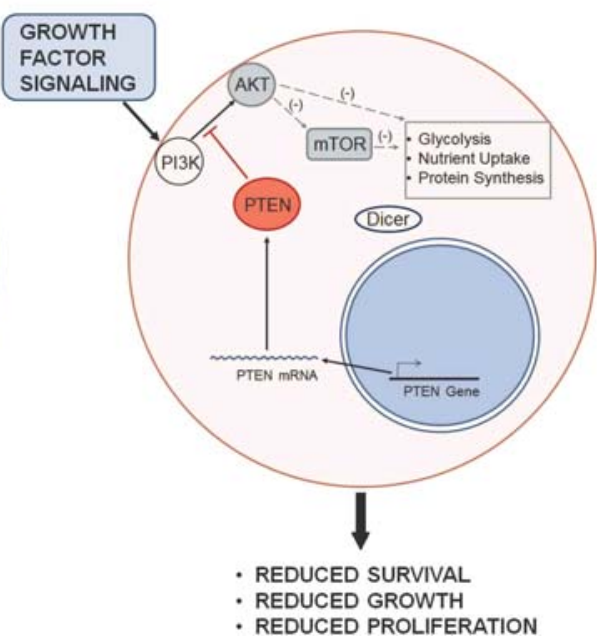

Figure 1. miR-181 regulation of PTEN controls PI3K signaling. PI3K activates AKT and mTOR in response to growth factor signaling, leading to promotion of nutrient uptake, protein synthesis, and increased glycolysis. The phosphatase PTEN negatively regulates PI3K activity. In proliferating thymocytes miR-181-posttranscriptionally represses PTEN expression in response to increased metabolic demands. This leads to increased activity of PI3K, AKT, and mTOR, allowing the cells to meet the metabolic requirements for survival, growth, and proliferation. In miR-181-deficient mice (right), the absence of miR-181 leads to increased PTEN activity, inhibiting PI3K pathway activity and therefore AKT and mTOR activation. This prevents the cells from making the metabolic adjustments required for growth and proliferation, leading to disruption of thymocyte development and a block in NKT cell development. In summary, miR-181 regulates the activity of the PI3K pathway through control of PTEN expression to meet the metabolic requirements of cell growth and proliferation (Henao-Mejia et al. 2013). (Adapted from Vacchio and Bosselut 2013.) 
requirement for the generation of nucleotides, amino acids, and lipids. Whereas differentiated cells rely primarily on oxidative phosphorylation to produce energy, proliferating cells switch to aerobic glycolysis to allow simultaneous energy production and biomass generation (Vander Heiden et al. 2009). This metabolic switch requires the transcriptional up-regulation of metabolic enzymes in numerous energetic and biosynthetic pathways. In parallel, key transporters (such as Glut1) are up-regulated to provide essential nutrients to the cell (Juntilla et al. 2007). Finally, translational capacity is increased to meet elevated demands for protein synthesis during growth and proliferation (Hay and Sonenberg 2004). Each of these events is tightly coordinated by PI3K signaling and thus strict control of the PI3K pathway is critical to regulate growth and proliferation.

Consistent with a role of miR-181 in regulating the PI3K/PTEN signaling axis, loss of miR-181a1/b1 in thymocytes induces a major metabolic reprogramming. This is evident as dysregulated expression of key components of the glycolytic pathway, pentose phosphate pathway, and nucleotide biosynthetic pathways. Thus, miR-181a1/b1deficient cells fail to fully reach the biosynthetic potential of normal proliferating thymocytes. As a functional consequence, miR-181-deficient cells display suboptimal glucose uptake, reduced glycolytic rates, and impaired metabolic fitness (Henao-Mejia et al. 2013).

\section{The PI3K/PTEN/miR-181 Axis in T-Cell and NKT-Cell Development}

The PI3K-directed metabolic changes described above are required to support appropriate thymocyte and NKTcell development. This is highlighted by the characteristic developmental phenotypes associated with impaired metabolic fitness in the thymus of mice with targeted deletion of individual components of the PI3K pathway (Sasaki et al. 2000; Hinton et al. 2004; Webb et al. 2005; Swat et al. 2006; Fayard et al. 2007, 2010; Ji et al. 2007; Juntilla et al. 2007; Finlay et al. 2010). Strikingly, miR$181 \mathrm{a} 1 / \mathrm{b} 1-d e f i c i e n t$ thymocytes recapitulate numerous phenotypes displayed in PI3K-deficient animals; these include thymic hypocellularity, decreased percentage of double-negative 1 thymocytes (DN1), maintained expression of CD25 on double-negative 3 thymocytes (DN3) and double-positive (DP) thymocytes, increased apoptosis, and decreased proliferation of DP thymocytes, and dysregulation of FOXO target genes (Henao-Mejia et al. 2013).

Generation of NKT cells also occurs in the thymus, branching from the conventional T-cell developmental pathway. Unlike conventional T cells, PI3K signaling is absolutely essential for the generation of NKT cells; PDK1-deficient animals show a strong developmental block during the metabolically demanding proliferative expansion phase of early NKT development (Finlay et al. 2010). In addition, Fedeli et al. showed that deletion of the miRNA-processing enzyme Dicer in thymocytes also leads to an almost complete absence of NKT cells, pro- viding the first evidence that miRNAs are important in NKT development (Fedeli et al. 2009). Interestingly, the PDK1 and Dicer phenotypes are remarkably similar, which led us to speculate that miRNAs are likely regulating important metabolic adaptions required for NKT development. Indeed, similar to what has been shown in PDK1- and Dicer-deficient animals, miR-181 deficiency resulted in a developmental block and reduced proliferation during the early stages NKT development (HenaoMejia et al. 2013). These findings, in combination with experiments that showed that genetic reduction of PTEN levels in miR-181-deficient mice rescued the great majority of aberrant phenotypes, firmly establish miR-181 as a key cellular metabolic rheostat through its tight regulation of PTEN expression.

These findings also reveal that NKT cells are particularly sensitive to metabolic dysregulation; this is potentially explained by a number of aspects unique to NKT development. First, NKT cells must undergo an additional burst of proliferation after diverging from the T-cell lineage (Dose et al. 2009). Second, NKT cells have a limited T-cell receptor (TCR) repertoire that requires extended survival to allow sufficient time for rearrangement of distal TCR- $\alpha$ genes (Guo et al. 2002; D'Cruz et al. 2010). Third, expression of MYC, which is selectively required at an early stage of NKT development, is downstream from PI3K (Dose et al. 2009; Mycko et al. 2009).

\section{Redundancy in the miR-181 Family}

MicroRNAs are predicted to target a great proportion of the genes expressed by the mammalian genome. However, loss-of-function experiments have rendered disappointing results because most individual miRNA mutants show no gross phenotypes (Ebert and Sharp 2012). A partial explanation for this phenomenon resides in the functional redundancy of many miRNAs that share their seed sequences. Thus, to reveal the complete range of miRNA functions in knockout animal models, it might be necessary to ablate all members of an miRNA family.

In agreement with this concept of functional redundancy, mice lacking multiple miR-181 alleles displayed immune phenotypes in B-cell development and T-cell homeostatic proliferation not observed in single deficient animals. In addition, miR-181a1/b1; miR-181a2/b2 double knockout mice showed reduced survival when compared to littermates as well as a significant reduction in body size (Fig. 2) (Henao-Mejia et al. 2013). Furthermore, triple knockout mice have never been obtained, suggesting that complete deficiency of the miR-181 family is lethal. The striking gene dose-dependent reduction in organism size and viability highlights that the miR-181 family plays an essential role in growth and/or development at the cellular and organism level.

\section{CONCLUSIONS}

Metabolic regulation is emerging as a principal mechanism to actively control cellular function, growth, pro- 


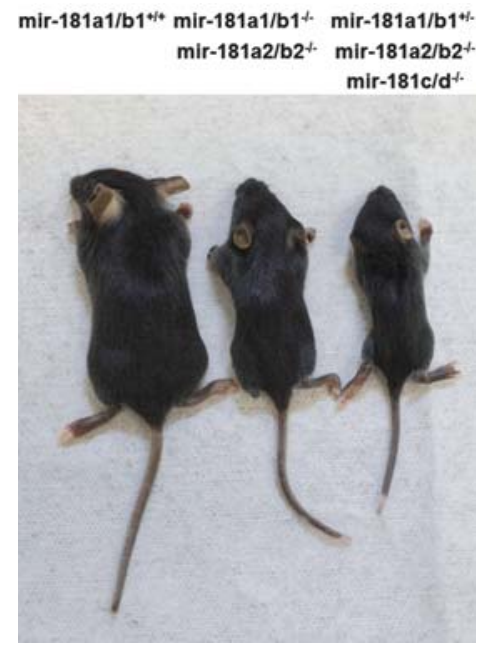

Figure 2. Gene dosage-dependent reduction in body size on deletion of multiple miR-181 alleles. Representative photograph showing size differences between age matched mir-181al/ $\mathrm{bl}^{+/+}, \quad$ mir-181a1 $/ \mathrm{bl}^{-/-} /$mir-181a2 $/ \mathrm{b2}^{-/-}$, and mir$181 a 1 / b 1^{+/-} /$mir-181a2 $/ b 2^{-/-} /$mir-181c/d $d^{-1-}$ mice.

liferation, and survival of immune cells. Our work has revealed that the miR-181 family is a nonredundant critical metabolic rheostat at the cellular and organismal level, highlighting this as one of the most important
miRNA families described to date. Moreover, its ubiquitous expression positions this miRNA family as a primary regulator of global metabolic fitness. The functional significance of this finding is underscored by the dramatic phenotypes observed on genetic ablation of miR-181 family members. In addition, the miR-181 family is highly conserved from bony fish to humans and a number of the miR-181 target sites in the $3^{\prime}$ UTR of PTEN are conserved across species; therefore, it is possible that this family of miRNAs has evolved to provide anabolic robustness during development. Although miR-181 is a central metabolic regulator during development and homeostasis, it has also been implicated in disease. Indeed, whereas PTEN down-regulation is associated with cancer and obesity, overexpression of miR-181 is found in a variety of solid tumors and leukemias (Calin et al. 2005; Carracedo et al. 2011; Jones et al. 2012). Thus, dysregulation of the miR-181-PTEN axis may drive development of cancer and metabolic syndrome.

Importantly, these findings must be considered in the context of a growing body of literature linking miRNAs to metabolic regulation. Indeed it is now apparent that many metabolic and biosynthetic pathways are regulated by miRNAs (Fig. 3). Given the importance of metabolism and the pathological consequences associated with metabolic dysregulation these findings are not surprising. Although very little is known regarding in vivo physiological relevance of these interactions, it is highly likely

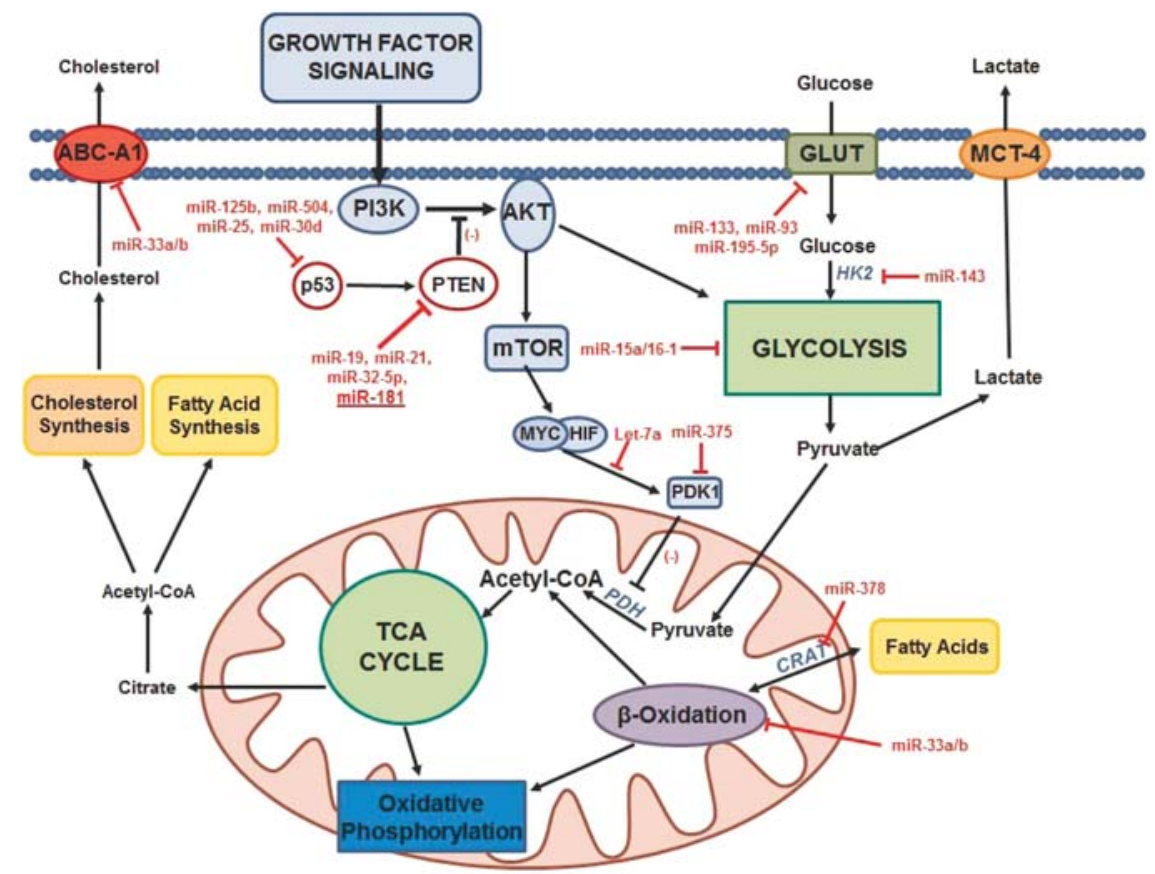

Figure 3. MicroRNA control of metabolism. MicroRNAs have been shown to regulate many stages in metabolism through modulation of the expression of key metabolic enzymes (e.g., hexokinase-2 by miR-133), transporters (e.g., GLUT 3 by miR195-5p), or pathways that control metabolism such as the PI3K pathway (e.g., regulation of PTEN by miR-19, miR-21, and miR-181). The figure illustrates several metabolic pathways, with key areas of microRNA influence indicated by red markers (Sampson et al. 2007; El Ouaamari et al. 2008; Pezzolesi et al. 2008; Horie et al. 2009; Le et al. 2009; Olive et al. 2009; He et al. 2010; Hu et al. 2010; Davalos et al. 2011; Jiang et al. 2011, 2012; Kumar et al. 2011; Ma et al. 2011; Carrer et al. 2012; Fang et al. 2012; Fei et al. 2012; Gregersen et al. 2012; Chen et al. 2013; Henao-Mejia et al. 2013; Peschiaroli et al. 2013; Zhu et al. 2013). (Adapted from Chen et al. 2012.) 
that a network of miRNAs will act in concert to determine the metabolic status of immune cells. Finally, because of its privileged status as a robust suppressor of PTEN in vivo, we propose that at miR-181 will play a dominant role in this network acting as the principle guardian of cellular and organismal metabolic regulation.

\section{ACKNOWLEDGMENTS}

We thank Caroline Lieber for assistance with manuscript preparation. J.H.-M. was supported by a Leukemia and Lymphoma Society Postdoctoral Fellowship. C.C.D.H. is supported by a Gruber Science Fellowship. This work was supported in part by the Howard Hughes Medical Institute (R.A.F.). The authors report no conflict of interest.

\section{REFERENCES}

Alimonti A, Carracedo A, Clohessy JG, Trotman LC, Nardella C, Egia A, Salmena L, Sampieri K, Haveman WJ, Brogi E, et al. 2010. Subtle variations in Pten dose determine cancer susceptibility. Nat Genet 42: 454-458.

Araki K, Turner AP, Shaffer VO, Gangappa S, Keller SA, Bachmann MF, Larsen CP, Ahmed R. 2009. mTOR regulates memory CD8 T-cell differentiation. Nature 460: 108-112.

Barthel A, Okino ST, Liao J, Nakatani K, Li J, Whitlock JP Jr, Roth RA. 1999. Regulation of GLUT1 gene transcription by the serine/threonine kinase Akt1. J Biol Chem 274: 20281 20286.

Calin GA, Ferracin M, Cimmino A, Di Leva G, Shimizu M, Wojcik SE, Iorio MV, Visone R, Sever NI, Fabbri M, et al. 2005. A MicroRNA signature associated with prognosis and progression in chronic lymphocytic leukemia. $N$ Engl J Med 353: $1793-1801$.

Carracedo A, Alimonti A, Pandolfi PP. 2011. PTEN level in tumor suppression: How much is too little? Cancer Res 71: 629-633.

Carrer M, Liu N, Grueter CE, Williams AH, Frisard MI, Hulver MW, Bassel-Duby R, Olson EN. 2012. Control of mitochondrial metabolism and systemic energy homeostasis by microRNAs 378 and 378*. Proc Natl Acad Sci 109: 15330-15335.

Chen B, Li H, Zeng X, Yang P, Liu X, Zhao X, Liang S. 2012. Roles of microRNA on cancer cell metabolism. J Transl Med 10: 228

Chen YH, Heneidi S, Lee JM, Layman LC, Stepp DW, Gamboa GM, Chen BS, Chazenbalk G, Azziz R. 2013. miRNA-93 inhibits GLUT4 and is overexpressed in adipose tissue of polycystic ovary syndrome patients and women with insulin resistance. Diabetes 62: 2278-2286.

Chi H. 2012. Regulation and function of mTOR signalling in $\mathrm{T}$ cell fate decisions. Nat Rev Immunol 12: 325-338.

Cobbold SP, Adams E, Nolan KF, Regateiro FS, Waldmann H. 2010. Connecting the mechanisms of T-cell regulation: Dendritic cells as the missing link. Immunol Rev 236: 203-218.

Davalos A, Goedeke L, Smibert P, Ramirez CM, Warrier NP, Andreo U, Cirera-Salinas D, Rayner K, Suresh U, Pastor-Pareja JC, et al. 2011. miR-33a/b contribute to the regulation of fatty acid metabolism and insulin signaling. Proc Natl Acad Sci 108: 9232-9237.

D'Cruz LM, Knell J, Fujimoto JK, Goldrath AW. 2010. An essential role for the transcription factor HEB in thymocyte survival, Tcra rearrangement and the development of natural killer T cells. Nat Immunol 11: 240-249.

Dose M, Sleckman BP, Han J, Bredemeyer AL, Bendelac A, Gounari F. 2009. Intrathymic proliferation wave essential for $\mathrm{V} \alpha 14^{+}$natural killer T cell development depends on cMyc. Proc Natl Acad Sci 106: 8641-8646.
Ebert MS, Sharp PA. 2012. Roles for microRNAs in conferring robustness to biological processes. Cell 149: $515-524$.

Ebert PJ, Jiang S, Xie J, Li QJ, Davis MM. 2009. An endogenous positively selecting peptide enhances mature $\mathrm{T}$ cell responses and becomes an autoantigen in the absence of microRNA miR-181a. Nat Immunol 10: 1162-1169.

El Ouaamari A, Baroukh N, Martens GA, Lebrun P, Pipeleers D, van Obberghen E. 2008. miR-375 targets 3'-phosphoinositide-dependent protein kinase-1 and regulates glucose-induced biological responses in pancreatic $\beta$-cells. Diabetes 57: $2708-2717$.

Fang R, Xiao T, Fang Z, Sun Y, Li F, Gao Y, Feng Y, Li L, Wang Y, Liu X, et al. 2012. MicroRNA-143 (miR-143) regulates cancer glycolysis via targeting hexokinase 2 gene. J Biol Chem 287: 23227-23235.

Fayard E, Gill J, Paolino M, Hynx D, Hollander GA, Hemmings BA. 2007. Deletion of PKB $\alpha /$ Akt1 affects thymic development. PLoS One 2: e992.

Fayard E, Moncayo G, Hemmings BA, Hollander GA. 2010. Phosphatidylinositol 3-kinase signaling in thymocytes: The need for stringent control. Sci Signal 3: re5.

Fedeli M, Napolitano A, Wong MP, Marcais A, de Lalla C, Colucci F, Merkenschlager M, Dellabona P, Casorati G. 2009. Dicer-dependent microRNA pathway controls invariant NKT cell development. J Immunol 183: 2506-2512.

Fei X, Qi M, Wu B, Song Y, Wang Y, Li T. 2012. MicroRNA195-5p suppresses glucose uptake and proliferation of human bladder cancer T24 cells by regulating GLUT3 expression. FEBS Lett 586: 392-397.

Finlay DK, Kelly AP, Clarke R, Sinclair LV, Deak M, Alessi DR, Cantrell DA. 2010. Temporal differences in the dependency on phosphoinositide-dependent kinase 1 distinguish the development of invariant V $\alpha 14$ NKT cells and conventional T cells. J Immunol 185: 5973-5982.

Fox CJ, Hammerman PS, Thompson CB. 2005. Fuel feeds function: Energy metabolism and the T-cell response. Nat Rev Immunol 5: 844-852.

Frauwirth KA, Thompson CB. 2002. Activation and inhibition of lymphocytes by costimulation. J Clin Invest 109: 295-299.

Garcia-Cao I, Song MS, Hobbs RM, Laurent G, Giorgi C, de Boer VC, Anastasiou D, Ito K, Sasaki AT, Rameh L, et al. 2012. Systemic elevation of PTEN induces a tumor-suppressive metabolic state. Cell 149: 49-62.

Gottlob K, Majewski N, Kennedy S, Kandel E, Robey RB, Hay N. 2001. Inhibition of early apoptotic events by Akt/PKB is dependent on the first committed step of glycolysis and mitochondrial hexokinase. Genes Dev 15: 1406-1418.

Gregersen LH, Jacobsen A, Frankel LB, Wen J, Krogh A, Lund AH. 2012. MicroRNA-143 down-regulates Hexokinase 2 in colon cancer cells. BMC Cancer 12: 232.

Guo J, Hawwari A, Li H, Sun Z, Mahanta SK, Littman DR, Krangel MS, He YW. 2002. Regulation of the TCR $\alpha$ repertoire by the survival window of $\mathrm{CD} 4^{+} \mathrm{CD} 8^{+}$thymocytes. Nat Immunol 3: 469-476.

Hay N, Sonenberg N. 2004. Upstream and downstream of mTOR. Genes Dev 18: 1926-1945.

He XY, Chen JX, Zhang Z, Li CL, Peng QL, Peng HM. 2010. The let-7a microRNA protects from growth of lung carcinoma by suppression of k-Ras and c-Myc in nude mice. J Cancer Res Clin Oncol 136: 1023-1028.

Henao-Mejia J, Williams A, Goff LA, Staron M, Licona-Limon P, Kaech SM, Nakayama M, Rinn JL, Flavell RA. 2013. The microRNA miR-181 is a critical cellular metabolic rheostat essential for NKT cell ontogenesis and lymphocyte development and homeostasis. Immunity 38: 984-997.

Hinton HJ, Alessi DR, Cantrell DA. 2004. The serine kinase phosphoinositide-dependent kinase 1 (PDK1) regulates $\mathrm{T}$ cell development. Nat Immunol 5: 539-545.

Horie T, Ono K, Nishi H, Iwanaga Y, Nagao K, Kinoshita M, Kuwabara Y, Takanabe R, Hasegawa K, Kita T, et al. 2009. MicroRNA-133 regulates the expression of GLUT4 by targeting KLF15 and is involved in metabolic control in cardiac myocytes. Biochem Biophys Res Commun 389: 315-320. 
$\mathrm{Hu}$ W, Chan CS, Wu R, Zhang C, Sun Y, Song JS, Tang LH, Levine AJ, Feng Z. 2010. Negative regulation of tumor suppressor $\mathrm{p} 53$ by microRNA miR-504. Mol Cell 38: 689-699. Jacobs SR, Herman CE, Maciver NJ, Wofford JA, Wieman HL, Hammen JJ, Rathmell JC. 2008. Glucose uptake is limiting in $\mathrm{T}$ cell activation and requires CD28-mediated Akt-dependent and independent pathways. $J$ Immunol 180: 4476-4486.

Ji H, Rintelen F, Waltzinger C, Bertschy Meier D, Bilancio A, Pearce W, Hirsch E, Wymann MP, Ruckle T, Camps M, et al. 2007. Inactivation of PI3K $\gamma$ and PI3K $\delta$ distorts T-cell development and causes multiple organ inflammation. Blood 110: 2940-2947.

Ji J, Yamashita T, Budhu A, Forgues M, Jia HL, Li C, Deng C, Wauthier E, Reid LM, Ye QH, et al. 2009. Identification of microRNA-181 by genome-wide screening as a critical player in EpCAM-positive hepatic cancer stem cells. Hepatology 50: $472-480$.

Jiang S, Li C, Olive V, Lykken E, Feng F, Sevilla J, Wan Y, He L, Li QJ. 2011. Molecular dissection of the miR-17-92 cluster's critical dual roles in promoting Th1 responses and preventing inducible Treg differentiation. Blood 118: 5487-5497.

Jiang S, Zhang LF, Zhang HW, Hu S, Lu MH, Liang S, Li B, Li Y, Li D, Wang ED, et al. 2012. A novel miR-155/miR-143 cascade controls glycolysis by regulating hexokinase 2 in breast cancer cells. EMBO J 31: 1985-1998.

Jones KB, Salah Z, Del Mare S, Galasso M, Gaudio E, Nuovo GJ, Lovat F, LeBlanc K, Palatini J, Randall RL, et al. 2012. miRNA signatures associate with pathogenesis and progression of osteosarcoma. Cancer Res 72: 1865-1877.

Juntilla MM, Wofford JA, Birnbaum MJ, Rathmell JC, Koretzky GA. 2007. Akt1 and Akt2 are required for $\alpha \beta$ thymocyte survival and differentiation. Proc Natl Acad Sci 104: 1210512110.

Karreth FA, Tay Y, Perna D, Ala U, Tan SM, Rust AG, DeNicola G, Webster KA, Weiss D, Perez-Mancera PA, et al. 2011. In vivo identification of tumor-suppressive PTEN ceRNAs in an oncogenic BRAF-induced mouse model of melanoma. Cell 147: $382-395$.

Kuchen S, Resch W, Yamane A, Kuo N, Li Z, Chakraborty T, Wei L, Laurence A, Yasuda T, Peng S, et al. 2010. Regulation of microRNA expression and abundance during lymphopoiesis. Immunity 32: 828-839.

Kumar M, Lu Z, Takwi AA, Chen W, Callander NS, Ramos KS, Young KH, Li Y. 2011. Negative regulation of the tumor suppressor $p 53$ gene by microRNAs. Oncogene 30: $843-853$.

Le MT, Teh C, Shyh-Chang N, Xie H, Zhou B, Korzh V, Lodish HF, Lim B. 2009. MicroRNA-125b is a novel negative regulator of p53. Genes Dev 23: 862-876.

Lee DY, Jeyapalan Z, Fang L, Yang J, Zhang Y, Yee AY, Li M, Du WW, Shatseva T, Yang BB. 2010. Expression of versican $3^{\prime}$-untranslated region modulates endogenous microRNA functions. PLoS One 5: e13599.

Lopez-Rios F, Sanchez-Arago M, Garcia-Garcia E, Ortega AD, Berrendero JR, Pozo-Rodriguez F, Lopez-Encuentra A, Ballestin C, Cuezva JM. 2007. Loss of the mitochondrial bioenergetic capacity underlies the glucose avidity of carcinomas. Cancer Res 67: 9013-9017.

Ma X, Kumar M, Choudhury SN, Becker Buscaglia LE, Barker JR, Kanakamedala K, Liu MF, Li Y. 2011. Loss of the miR-21 allele elevates the expression of its target genes and reduces tumorigenesis. Proc Natl Acad Sci 108: 10144-10149.

Mycko MP, Ferrero I, Wilson A, Jiang W, Bianchi T, Trumpp A, MacDonald HR. 2009. Selective requirement for c-Myc at an early stage of $\mathrm{V} \alpha 14 \mathrm{i}$ NKT cell development. J Immunol 182: 4641-4648.

Myers MP, Pass I, Batty IH, Van der Kaay J, Stolarov JP, Hemmings BA, Wigler MH, Downes CP, Tonks NK. 1998. The lipid phosphatase activity of PTEN is critical for its tumor suppressor function. Proc Natl Acad Sci 95: 13513-13518.

Olive V, Bennett MJ, Walker JC, Ma C, Jiang I, Cordon-Cardo C, Li QJ, Lowe SW, Hannon GJ, He L. 2009. miR-19 is a key oncogenic component of mir-17-92. Genes Dev 23: 28392849 .
Ortega-Molina A, Efeyan A, Lopez-Guadamillas E, MunozMartin M, Gomez-Lopez G, Canamero M, Mulero F, Pastor J, Martinez S, Romanos E, et al. 2012. Pten positively regulates brown adipose function, energy expenditure, and longevity. Cell Metab 15: 382-394.

Parry R, Smith G, Reif K, Sansom DM, Ward S. 1997. Activation of the PI3 K effector protein kinase B following ligation of CD28 or Fas. Biochem Soc Trans 25: S589.

Patrick DM, Montgomery RL, Qi X, Obad S, Kauppinen S, Hill JA, van Rooij E, Olson EN. 2010. Stress-dependent cardiac remodeling occurs in the absence of microRNA-21 in mice. $J$ Clin Invest 120: 3912-3916.

Pearce EL, Pearce EJ. 2013. Metabolic pathways in immune cell activation and quiescence. Immunity 38: 633-643.

Peschiaroli A, Giacobbe A, Formosa A, Markert EK, Bongiorno-Borbone L, Levine AJ, Candi E, D'Alessandro A, Zolla L, Finazzi Agro A, et al. 2013. miR-143 regulates hexokinase 2 expression in cancer cells. Oncogene 32: 797-802.

Pezzolesi MG, Platzer P, Waite KA, Eng C. 2008. Differential expression of PTEN-targeting microRNAs miR-19a and miR-21 in Cowden syndrome. Am J Hum Genet 82: 11411149.

Poliseno L, Salmena L, Riccardi L, Fornari A, Song MS, Hobbs RM, Sportoletti P, Varmeh S, Egia A, Fedele G, et al. 2010. Identification of the miR-106b 25 microRNA cluster as a proto-oncogenic PTEN-targeting intron that cooperates with its host gene MCM7 in transformation. Sci Signal 3: ra29.

Sampson VB, Rong NH, Han J, Yang Q, Aris V, Soteropoulos P, Petrelli NJ, Dunn SP, Krueger LJ. 2007. MicroRNA let-7a down-regulates MYC and reverts MYC-induced growth in Burkitt lymphoma cells. Cancer Res 67: 9762-9770.

Sasaki T, Irie-Sasaki J, Jones RG, Oliveira-dos-Santos AJ, Stanford WL, Bolon B, Wakeham A, Itie A, Bouchard D, Kozieradzki I, et al. 2000. Function of PI3K $\gamma$ in thymocyte development, T cell activation, and neutrophil migration. Science 287: 1040-1046.

Sinclair LV, Finlay D, Feijoo C, Cornish GH, Gray A, Ager A, Okkenhaug K, Hagenbeek TJ, Spits H, Cantrell DA. 2008. Phosphatidylinositol-3-OH kinase and nutrient-sensing mTOR pathways control T lymphocyte trafficking. Nat Immunol 9: 513-521.

Song MS, Salmena L, Pandolfi PP. 2012. The functions and regulation of the PTEN tumour suppressor. Nat Rev Mol Cell Biol 13: 283-296.

Summers SA, Yin VP, Whiteman EL, Garza LA, Cho H, Tuttle RL, Birnbaum MJ. 1999. Signaling pathways mediating insulin-stimulated glucose transport. Ann NY Acad Sci 892: 169186.

Swat W, Montgrain V, Doggett TA, Douangpanya J, Puri K, Vermi W, Diacovo TG. 2006. Essential role of PI3K $\delta$ and PI3K $\gamma$ in thymocyte survival. Blood 107: 2415-2422.

Ueki K, Yamamoto-Honda R, Kaburagi Y, Yamauchi T, Tobe K, Burgering BM, Coffer PJ, Komuro I, Akanuma Y, Yazaki Y, et al. 1998. Potential role of protein kinase B in insulininduced glucose transport, glycogen synthesis, and protein synthesis. J Biol Chem 273: 5315-5322.

Vacchio MS, Bosselut R. 2013. T cell metabolism: MicroRNAs cap PTEN to feed the expanding crowd. Immunity 38: 847848.

Vander Heiden MG, Cantley LC, Thompson CB. 2009. Understanding the Warburg effect: The metabolic requirements of cell proliferation. Science 324: 1029-1033.

Ventura A, Young AG, Winslow MM, Lintault L, Meissner A, Erkeland SJ, Newman J, Bronson RT, Crowley D, Stone JR, et al. 2008. Targeted deletion reveals essential and overlapping functions of the miR-17 92 family of miRNA clusters. Cell 132: 875-886.

Webb LM, Vigorito E, Wymann MP, Hirsch E, Turner M. 2005. Cutting edge: $\mathrm{T}$ cell development requires the combined activities of the p110 $\gamma$ and $p 110 \delta$ catalytic isoforms of phosphatidylinositol 3-kinase. J Immunol 175: 2783-2787. 


\section{WILLIAMS ET AL.}

Xiao C, Srinivasan L, Calado DP, Patterson HC, Zhang B, Wang J, Henderson JM, Kutok JL, Rajewsky K. 2008. Lymphoproliferative disease and autoimmunity in mice with increased miR-17-92 expression in lymphocytes. Nat Immunol 9: 405414.

Zhang L, Deng T, Li X, Liu H, Zhou H, Ma J, Wu M, Zhou M, Shen S, Niu Z, et al. 2010. microRNA-141 is involved in a nasopharyngeal carcinoma-related genes network. Carcinogenesis 31: $559-566$.

Zhu G, Chai J, Ma L, Duan H, Zhang H. 2013. Downregulated microRNA-32 expression induced by high glucose inhibits cell cycle progression via PTEN upregulation and Akt inactivation in bone marrow-derived mesenchymal stem cells. Biochem Biophys Res Commun 433: 526-531. 


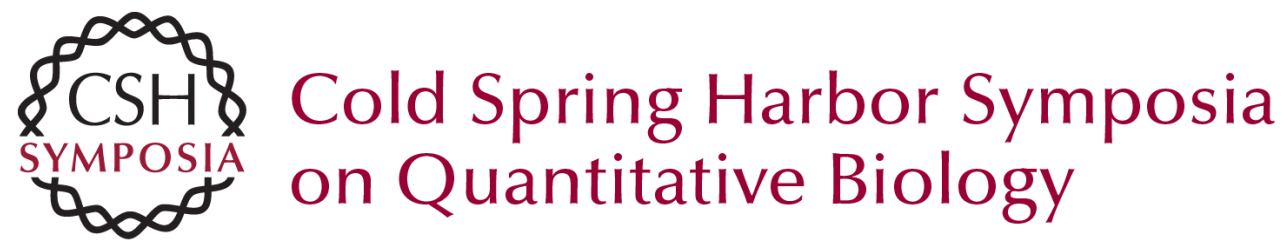

\section{miR-181 and Metabolic Regulation in the Immune System}

Adam Williams, Jorge Henao-Mejia, Christian C. D. Harman, et al.

Cold Spring Harb Symp Quant Biol 2013 78: 223-230 originally published online October 25, 2013

Access the most recent version at doi:10.1101/sqb.2013.78.020024

References This article cites 72 articles, 33 of which can be accessed free at: http://symposium.cshlp.org/content/78/223.full.html\#ref-list-1

\section{License}

Email Alerting

Receive free email alerts when new articles cite this article - sign up in

Service the box at the top right corner of the article or click here. 